\title{
Involvement of brassinosteroids and ethylene in the control of mitochondrial electron transport chain in postharvest papaya fruit
}

\author{
Luis Miguel Mazorra', Marcos Goes Oliveira², Anderson Fernandes Souza², Willian \\ Batista da Silva², Gláucia Michelle dos Santos², Lígia Renata Almeida da Silva², \\ Marcelo Gomes da Silva ${ }^{3}$, Carlos Guillermo Bartoli ${ }^{1}$, Jurandi Gonçalves de Oliveira ${ }^{2 *}$
}

'Instituto de Fisiología Vegetal (INFIVE), Universidad Nacional de La Plata, CCT CONICET La Plata, La Plata, Argentina.

${ }^{2}$ Setor de Fisiologia Vegetal, LMGV, Universidade Estadual do Norte Fluminense (UENF), Campos dos Goytacazes, RJ, Brazil.

${ }^{3}$ Setor de Fenômenos Fototérmicos, LCFIS, Universidade Estadual do Norte Fluminense (UENF), Campos dos Goytacazes, RJ, Brazil.

*Corresponding author: jugo@uenf.br

Received: 15 May 2013; Accepted: 01 August 2013

ABSTRACT: The plant hormones brassinosteroids (BR) and ethylene (ET) act together to regulate plant metabolism. We used BR and 1-methylcyclopropene (1-MCP, an ET action inhibitor) to elucidate the interactions between both hormones for the regulation of mitochondrial respiratory pathways in papaya fruit. The exogenous application of the 24-epibrassinolide (epiBR) enhanced the alternative oxidase (AOX) capacity. While treatment with Brz2001 ( $\mathrm{Brz}$ is a specific inhibitor of the BR synthesis) also enhanced AOX capacity, these effects lacked in fruit treated simultaneously with epiBR and Brz. Changing the BR level had no effect on ET emission rate in the first $24 \mathrm{~h}$, but a reduction in ET emission was observed in Brz-treated fruit on the fifth day. Together with Brz, epiBR increased the ET production on the fifth day, following the day in which the treatment was carried out. When the ET sensitivity of fruit was inhibited by the application of 1-MCP, the effects of epiBR and Brz were opposite to those obtained without 1-MCP. AOX capacity was slightly inhibited by epiBR in fruit pre-treated with 1-MCP. Data suggest that BR and ET act antagonistically, therefore regulating, directly or indirectly, AOX capacity during papaya fruit ripening.

KEYWORDS: AOX capacity, (CN)-insensitive respiration, ethylene sensitivity, 1-methylcyclopropene.

\section{INTRODUCTION}

Plant mitochondrial electron transport chain (ETC) has two terminal oxidases: the cytochrome c oxidase (COX), which catalyzes the four-electron reduction of $\mathrm{O}_{2}$ to $\mathrm{H}_{2} \mathrm{O}$, and an alternative oxidase (AOX). While electrons in the COX pathway pass from ubiquinol to complex III, cytochrome $\mathrm{c}$ and, finally, COX, the AOX directly couples the oxidation of ubiquinol with the reduction of $\mathrm{O}_{2}$ to $\mathrm{H}_{2} \mathrm{O}$. Therefore, $\mathrm{AOX}$ introduces a branch in the ETC, so the electrons in ubiquinol are partitioned between the COX and the AOX (Vanlerberghe 2013).

ETC via COX is coupled with proton translocation, and the resulting proton motive force is used to generate ATP. However, the AOX pathway is not proton pumping, since electrons flowing to AOX bypass the proton pump via COX pathway. Therefore, AOX reduces the ATP yield of respiration. AOX is strongly induced at the transcript and protein levels by dysfunctions of the COX pathway and disruptions in respiration metabolism. However, no changes in the amount of AOX in response to changes in ETC have been reported. AOX expression is likely to be responsive to multiple and complex signals, including plant hormones, reactive oxygen species (ROS), and respiration metabolites (Vanlerberghe 2013).

AOX is subjected to a prominent biochemical control, which regulates the protein amount and the partitioning of electrons between AOX and COX pathways. The plant AOX exists as a homodimer. The dimer may be either non-covalently 
linked (reduced active form) or covalently linked by a regulatory disulfide bond between the two monomers (oxidized inactive form). The reduction of AOX into its active form is facilitated by NADH. Once in its reduced form, AOX is sensitive to activation by specific $\alpha$-keto acids, most notably pyruvate (Carré et al. 2011). The maximum possible flux of electrons to AOX is often named AOX capacity. This is generally defined as the $\mathrm{O}_{2}$ uptake resistant to COX pathway inhibitor and sensitive to AOX inhibitor. This capacity measure typically reflects AOX protein abundance, but it does not give any indication of the actual flux of electrons to AOX (i.e., AOX activity) (Vanlerberghe 2013).

The contribution of the AOX pathway to the ripening of climacteric fruits has not been clarified. Some reports suggest that the expression of AOX protein and the (CN)-insensitive respiration decreases during the tomato postharvest ripening (Almeida et al. 1999, Jarmuszkiewicz et al. 2000). On the other hand, increasing AOX protein levels and enhanced (CN)insensitive respiration were also observed (Considine et al. 2001).

Brassinosteroids (BRs) are considered as a new class of plant hormone which modulates plant growth and development. BRs have been found to regulate ethylene levels (Arteca and Arteca 2008). Thus, in vegetative tissues, exogenous BRs induce ethylene production and modulate ethylene-mediated growth response (De Grauwe et al. 2005, Arteca and Arteca 2008). In addition, the potential interaction between both hormones has been revealed as being antagonistic or synergistic effects in Arabidopsis (De Grauwe et al. 2005, Deslauriers and Larsen 2010). BR downstream signaling is required for ethylene-induced apical hook formation (Gendron et al. 2008). However, in some fruit species, such as mango and strawberry, endogenous BRs occur in trace amounts and may not be critical for fruit ripening (Zaharah et al. 2011, Symons et al. 2012). In fact, the climacteric burst of ethylene production occurs without fluctuations of the low BR levels in ripened fruit (Zaharah et al. 2011), but applied BRs induce ethylene production (Vardhini and Rao 2002, Zaharah et al. 2011), suggesting that part of the ET response can be $\mathrm{BR}$ independent.

In contrast with some climacteric fruits, the ripening of postharvest papaya fruit displays intriguing characteristics. Ripening-related changes happen very quickly in papaya (Fabi et al. 2007, Oliveira and Victoria 2011). Besides, respiration is increased, but it sometimes decreases when the fruit becomes fully ripened (Bron and Jacomino 2006). Moreover, fruit can show increased respiration without significant ethylene peak (Bron and Jacomino 2006). Even when there is ethylene burst, the maximum respiration rate occurs (Wills and Widjanarko
1995). However, the processes regulating the AOX pathway in papaya fruit ripening have not been well established. Our group demonstrated the involvement of the AOX pathway in fruit respiratory activity occurring at the end of papaya ripening (unpublished results).

A biochemical approach that combines the use of BR and ET-related inhibitors might elucidate the potential interaction between both hormones in postharvest papaya ripening. When applied, BR biosynthesis inhibitors specifically inhibit BR biosynthetic cytochrome P-450 enzymes and reduce the amount of endogenous BRs in different plant tissues (Asami et al. 2003). The Brz2001, a specific brassinosteroid biosynthesis inhibitor, acts by blocking BR biosynthesis (Sekimata et al. 2001). Altered BR sensitivity and signaling induced by $\mathrm{BR}$ biosynthesis inhibitors are similar to BR-deficient tissues (Sekimata et al. 2001, Asami et al. 2003). The 1-methylcyclopropene (1-MCP) specifically binds to ET receptors, thus antagonizing ET response (Blankenship and Dole 2003), so its effects in papaya fruit can persist for a long time (Fabi et al. 2007). The resulting effect resembles several ET-insensitivity responses such as the inhibition of papaya ripening (Souza et al. 2009). Therefore, treatment with 1-MCP reduced ET production and respiration in papaya and mango fruit (Lalel et al. 2003, Souza et al. 2009). With the manipulation of the BR/ET ratio, by using Brz and 1-MCP, this paper tests the hypothesis that BRs and ET influence AOX capacity in the ripening of papaya fruit.

\section{MATERIAL AND METHODS}

Plant material: Papaya fruit (Carica papaya L.), cultivar "Golden", was used throughout this study. Fruits were harvested from a commercial production center located in the region of Linhares (19¹5'S, 39051'70”W), state of Espírito Santo, Brazil, in July 2012. After being harvested, the fruits were transported at $15^{\circ} \mathrm{C}$ to the laboratory, and the time from harvest to arrival was of about $5 \mathrm{~h}$. For all the further experiments, fruits were chosen on the basis of homogenous ripening at maturity stage 1 as indicated by Souza et al. (2009).

Fruit treatment with BR-related compounds: Initial experiments designed to explore the involvement of BRs on the postharvest papaya fruit ripening were performed. Homogenous fruits were then chosen, and the fruit peduncle was dipped in solutions of the different compounds, and immediately vacuum-infiltrated for $5 \mathrm{~min}$. These solutions contained $1 \mu \mathrm{M}$ of 24-epibrassinolide (epiBR, a naturally occurring brassinosteroid); $10 \mu \mathrm{M}$ of Brz2001 (Brz, a specific inhibitor of brassinosteroid biosynthesis); or a mixture of 
both compounds with the aforementioned concentrations. Both epiBR and Brz were dissolved in ethanol to get stock solutions before being diluted to designated concentrations with distilled water. Control fruit were infiltrated with distilled water containing $0.5 \%(\mathrm{v} / \mathrm{v})$ ethanol, which was also present in the compound solutions. Once infiltrated, both treated and control fruits were allowed to ripen in a dark chamber at $25 \pm 1^{\circ} \mathrm{C}$ and $80 \pm 5 \%$ relative humidity for $5 \mathrm{~d}$.

\section{Treatment with 1-methylcyclopropene: Further} experiments were carried out to evaluate the participation of ethylene response in the effects induced by BRs. Before any treatment with BR-related solutions, all fruits were placed into hermetically sealed containers that were in a chamber at $25^{\circ} \mathrm{C}$. Then, fruits were incubated with $1.0 \mu \mathrm{L} \mathrm{L}^{-1}$ of the 1-MCP (an ethylene action inhibitor) for more than $12 \mathrm{~h}$ as previously described (Souza et al. 2009). Fruits incubated in the absence of 1-MCP served as control. Subsequently, treated fruits were immediately infiltrated with the solutions of the BR-related chemicals as already indicated and stored in a dark chamber at $25 \pm 1^{\circ} \mathrm{C}$ and $80 \pm 5 \%$ relative humidity, and allowed to ripen for $5 \mathrm{~d}$.

Ethylene emission and respiration rate: Real-time measurements of ethylene and $\mathrm{CO}_{2}$ production were performed using a photoacoustic spectrometer coupled with an infrared gas analyzer according to Silva et al. (2003). Ethylene production was determined using a laser driven photoacoustic system based on infrared absorption. This technique detects ethylene concentrations of parts per billion (Voesenek et al. 1990). Fruit respiration rates ( $\mathrm{CO}_{2}$ emissions) were monitored by the use of a commercial infrared detector (URAS14, ABB), connected to the spectrometer outlet. As a carrier gas, compressed laboratory air was used to push the emitted gases from the fruits into the photoacoustic cell at a $2 \mathrm{~L} \mathrm{~h}^{-1}$ flow. Ethylene and $\mathrm{CO}_{2}$ production rates were expressed as $\mu \mathrm{L} \mathrm{kg}^{-1} \mathrm{~h}^{-1}$ and $\mathrm{mL} \mathrm{kg}^{-1} \mathrm{~h}^{-1}$, respectively (fresh weight).

Each fruit was weighed and individually placed in a glass container coupled to the spectrometer. Subsequently, gas exchange measurements were recorded. Values from six independent fruit evaluations per treatment were pooled and averaged.

\section{Respiratory activity in isolated mitochondria}

Isolation of the mitochondria: The mitochondria were isolated at $4^{\circ} \mathrm{C}$ employing about $300 \mathrm{~g}$ of pulp from the same fruit used for ethylene and respiration emission analyses. The tissue was homogenized by means of a juice extractor using the blender mode (Juicer, model R16720, Walita, Brazil) in 1.0 L of isolation buffer [0.35 M mannitol, $50 \mathrm{mM}$ MOPS, $3 \mathrm{mM}$ EDTA, $8 \mathrm{mM}$ Cys, 0.1\% (w/v) BSA, 0.4\% (w/v) PVP-25, pH 7.4] with constant stirring. The homogenate was filtered through four layers of gauze and a Miracloth (Calbiochem, CA, USA), centrifuged at $1,500 \times \mathrm{g}$ for $15 \mathrm{~min}$. The supernatant was then centrifuged at $15,000 \times \mathrm{g}$ for $15 \mathrm{~min}$, and the pellet was resuspended in washing buffer $[0.35 \mathrm{M}$ mannitol, $10 \mathrm{mM}$ MOPS, $0.5 \mathrm{mM}$ EDTA, 0.1\% (w/v) BSA, pH 7.2]. This suspension was centrifuged at $1,000 \mathrm{x} g$ for $8 \mathrm{~min}$ and the supernatant was again centrifuged at 9,000 $\mathrm{g}$ for $15 \mathrm{~min}$ in order to obtain the mitochondrial crude extract for respiratory activity assays.

The concentration of proteins was determined by spectrophotometry at $595 \mathrm{~nm}$, as described by Bradford (1976), using BSA as the standard protein.

Respiratory activity: For this step, $1 \mathrm{mg}$ of protein was used to determine the respiratory activity of mitochondria with a Clark $\mathrm{O}_{2}$ electrode (Hansatech, Respire 1, UK) in $1.0 \mathrm{~mL}$ of reaction medium [0.35 $\mathrm{M}$ mannitol, $10 \mathrm{mM}$ phosphate buffer, $10 \mathrm{mM} \mathrm{KCl}, 5 \mathrm{mM} \mathrm{MgCl}, 0.5 \%$ (w/v) BSA, pH 7.2] at $25^{\circ} \mathrm{C}$. The entire assay was carried out in the presence of $200 \mu \mathrm{M}$ of ATP, along with $10 \mathrm{mM}$ malate and $20 \mathrm{mM}$ glutamate as substrates for respiration. The addition of $100 \mathrm{nmol}$ of $\mathrm{ADP}$ to the reaction medium induced the transition from phosphorylation (State 3) to resting (State 4) respiration, demonstrating the phosphorylation capacity of the mitochondria.

\section{Determining the capacity of the alternative oxidase} (AOX) pathway: The cyanide-resistant respiratory pathway was evaluated by $\mathrm{AOX}$ activity by measuring the $\mathrm{O}_{2}$ consumption rate with mitochondria in the state 4 of phosphorylation (Duque and Arrabaça 1999).

AOX capacity was assessed using the aforementioned reaction medium supplemented with $2.5 \mu \mathrm{g}$ oligomycin and $300 \mu \mathrm{M}$ propranolol to inhibit ATP-synthase and the cellular anion channel, respectively (Beavis and Vercesi 1992, Martins et al. 1993, Calegario et al. 2003), along with the addition of $1 \mathrm{mM}$ dithiothreitol (DTT) and $0.15 \mathrm{mM}$ pyruvate to activate AOX (Wagner et al. 1995) and 0.5\% (w/v) BSA to inhibit the UcP activity. COX inhibition occurred by adding 3 $\mathrm{mM} \mathrm{KCN}$ to the reaction medium, while AOX was inhibited by the addition of $20 \mu \mathrm{M} n$-propyl gallate (PG).

The AOX pathway capacity was defined as being the $\mathrm{O}_{2}$ uptake resistant to the $\mathrm{COX}$ inhibitor $(\mathrm{KCN})$ and sensitive to the AOX inhibitor (PG) (Moller et al. 1988). A mixture of respiratory substrates was added to the reaction to make sure that respiration is not limited by the substrate supply.

The pulp of two fruits per treatment was pooled and used for each one of the three replicates. 
Statistical analysis: For each treatment, data from two independent experiments with three replicates were pooled and averaged. Statistical analysis was performed using at least six mean values by the Duncan test and significance was determined at $\mathrm{p} \leq 0.05$.

\section{RESULTS}

Based on the experience that ripening changes in papaya fruit take place very quickly, and that the rapid softening starts before the increased ethylene production and respiratory activity (Fabi et al. 2007), we characterized the alterations of pulp firmness, the emission of ethylene, and respiratory activity. Results showed that papaya fruit was ripe (pulp firmness $<20 \mathrm{~N}$ ) at $24 \mathrm{~h}$ and fully ripened on the $5^{\text {th }}$ day (supplementary data).

To test whether BRs influence ethylene production, papaya fruit was treated with $1 \mu \mathrm{M}$ of 24 -epibrassinolide, or $10 \mu \mathrm{M}$ of $\mathrm{Brz}$, or a combination of both compounds, and then ethylene emission was measured at $24 \mathrm{~h}$ and $5 \mathrm{~d}$ after the application of the treatment. We were not able to detect consistent differences in pulp firmness among the treatments at any time point (supplementary data). However, as shown in Figure 1, fruit showed relatively low ethylene emission rate $\left(<0.5 \mu \mathrm{L} \mathrm{h}^{-1} \mathrm{~kg}^{-1}\right)$ at $24 \mathrm{~h}$. No differences in ethylene emission rate were detected among treatments evaluated at this time point. Ethylene production increased $\left(\sim 3 \mu \mathrm{L} \mathrm{h}^{-1} \mathrm{~kg}^{-1}\right)$ in fully ripened fruit on day 5 , however, the lower increase in ethylene emission was observed in Brz-treated fruit. Interestingly, the

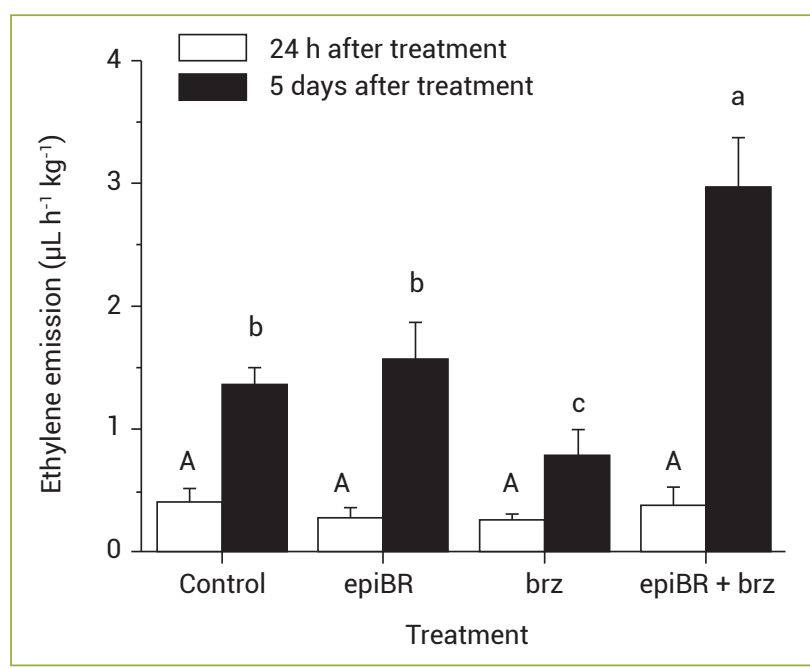

Figure 1. Average ethylene emission of the whole papaya fruit treated with $1 \mu \mathrm{M} 24$-epibrassinolide (epiBR), or $10 \mu \mathrm{M} \mathrm{Brz}$, or a combination of both compounds, and then evaluated at $24 \mathrm{~h}$ (black bars) and 5 days (white bars) after treatment application. Different letters represent significant differences among treatments as compared to the respective control (Duncan's test, $p \leq 0.05)$ within the same time of evaluation after treatment application ( $24 \mathrm{~h}$ : capital letters; and 5 days: small letters). rate of ethylene emission increased mostly in response to coapplications of epiBR and Brz.

To check whether BR content affects respiratory activity, the production of $\mathrm{CO}_{2}$ in control and treated fruits was also tested (Figure 2). As observed in ethylene emission, similar respiratory activities among treatments were detected in fruit evaluated at $24 \mathrm{~h}$. The respiration rate was not altered in fully ripened control fruit on the $5^{\text {th }}$ day; however, it was higher in the fruits subjected to chemical applications. Again, the cotreatment of epiBR with Brz showed the highest increase $(\sim 100 \%)$ in respiration on the $5^{\text {th }}$ day.

To get insights about whether or not BRs affect the maximum possible flux of electrons to AOX in postharvest papaya fruit, we measured the oxygen uptake resistant to cyanide and sensitive to AOX inhibitor in isolated mitochondria from control and treated fruit (Table 1). Among control fruit, the AOX capacity contributed with about $45 \%$ of the mitochondrial oxygen consumption, and this percentage remained almost unchanged in fully ripened fruit on the 5th day. Treating fruit with epiBR or Brz activated the AOX-related $\mathrm{O}_{2}$ consumption, showing the highest effect on BR inhibitortreated fruit on the $5^{\text {th }}$ day. However, the stimulatory effect of epiBR on the AOX capacity was lacking in fruits cotreated with Brz (Table 1).

The increased ethylene emission in fruits cotreated with the combination of $\mathrm{Brz}$ and epiBR suggests that this gaseous hormone is involved in BR-related effects. To test

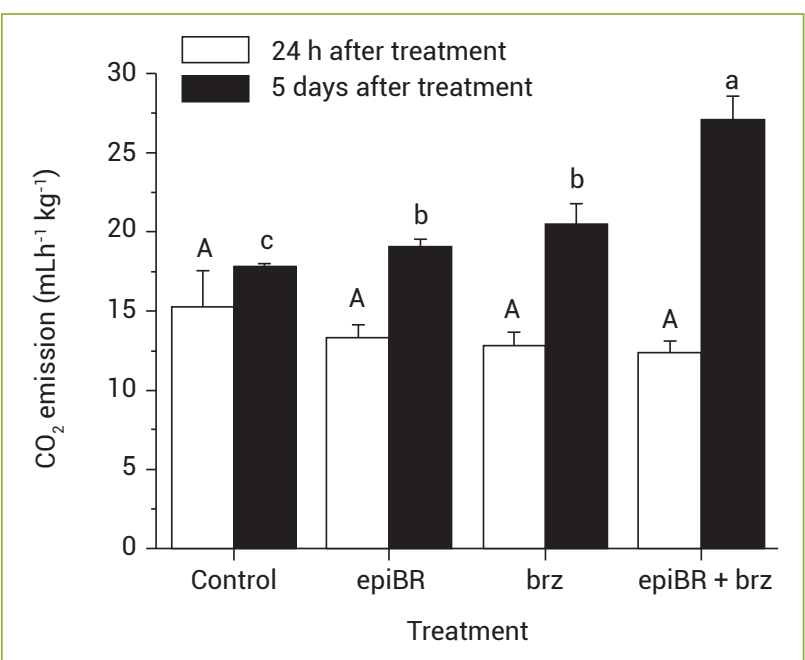

Figure 2. Average carbon dioxide production of the whole papaya fruit treated with $1 \mu \mathrm{M}$ 24-epibrassinolide (epiBR), or $10 \mu \mathrm{M} \mathrm{Brz}$, or a combination of both compounds, and then evaluated at $24 \mathrm{~h}$ (black bars) and 5 days (white bars) after treatment application. Different letters represent significant differences among treatments as compared to the respective control (Duncan's test, $p \leq 0.05)$ within the same time of evaluation after treatment application ( $24 \mathrm{~h}$ : capital letters; and 5 days: small letters). 
Table 1. Capacity of mitochondrial oxygen consumption dependent on alternative oxidase in papaya fruit evaluated at $24 \mathrm{~h}$ and $5 \mathrm{~d}$. Measurements were performed on isolated mitochondria from fruits treated with $1 \mu \mathrm{M} 24$-epibrassinolide (epiBR), or $10 \mu \mathrm{M} \mathrm{Brz}$, and a combination of both compounds

\begin{tabular}{lcc} 
Treatments & $24 \mathrm{~h}$ after treatment & $5 \mathrm{~d}$ after treatment \\
Control & $45.2^{\ddagger} \mathrm{C}^{*}$ & $48.1 \mathrm{c}$ \\
\hline epiBR & $62.5 \mathrm{a}$ & $55.7 \mathrm{~b}$ \\
$\mathrm{Brz}$ & $59.6 \mathrm{ab}$ & $72.7 \mathrm{a}$ \\
\hline $\mathrm{Brz}+$ epiBR & $52.4 \mathrm{bc}$ & $50.8 \mathrm{C}$ \\
\hline
\end{tabular}

*Different letters indicate significant differences among treatments as compared to the respective control (Duncan's test, $p \leq 0.05$ ). FValues are percentages of alternative oxidase-related oxygen consumption in relation to total consumption.

Table 2. Capacity of mitochondrial oxygen consumption related to alternative oxidase (AOX) in papaya fruit evaluated at $24 \mathrm{~h}$ and $5 \mathrm{~d}$. Measurements were performed in isolated mitochondria from fruits incubated with $1 \mathrm{~mL} \mathrm{~L}^{-1}$ of $1-\mathrm{MCP}$ and then treated with $1 \mathrm{mM}$ 24-epibrassinolide (epiBR), or $10 \mathrm{mM} \mathrm{Brz}$, or a combination of both compounds

\begin{tabular}{lcc} 
Treatments & $24 \mathrm{~h}$ after treatment & $5 \mathrm{~d}$ after treatment \\
1-MCP+Control & $75.6^{\ddagger} \mathrm{a}^{*}$ & $83.6 \mathrm{a}$ \\
\hline 1-MCP+epiBR & $66.0 \mathrm{~b}$ & $54.8 \mathrm{C}$ \\
\hline $1-\mathrm{MCP}+\mathrm{Brz}$ & $53.8 \mathrm{C}$ & $69.9 \mathrm{~b}$ \\
$1-\mathrm{MCP}+\mathrm{Brz}+$ epiBR & $57.7 \mathrm{C}$ & $66.1 \mathrm{~b}$ \\
\hline
\end{tabular}

*Different letters indicate significant differences among treatments as compared

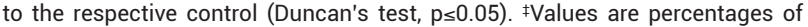
AOX-related oxygen consumption in relation to total consumption.

this hypothesis, another experiment was performed in which ethylene action was inhibited by treating fruit with 1-MCP, and then the capacity of the AOX pathway was measured in response to $\mathrm{Brz}$, epiBR, and $\mathrm{Brz}$ with epiBR.

Incubating fruit with $1 \mu \mathrm{L} \mathrm{L}^{-1}$ of $1-\mathrm{MCP}$ confirmed that this ethylene inhibitor is effective in papaya, as reported in previous papers (Manenoi et al. 2007, Souza et al. 2009) and demonstrated by the marked delay of fruit softening (data not shown). Results revealed $\sim 76-84 \%$ of the AOX pathway capacity in 1-MCP treated fruit (Table 2). However, when epiBR was applied to 1-MCP treated fruit, significant inhibition of the AOX capacity was detected. Furthermore, the treatment with Brz also decreased AOX capacity. The participation of AOX pathway on respiration was also reduced in the presence of coincubation between $\mathrm{Brz}$ and epiBR. Interestingly, epiBR did not show any effect on AOX capacity in Brz-treated fruit.

\section{DISCUSSION}

The fact of BRs and ET playing a role in AOX pathway during the ripening of climacteric fruits is yet to be explored. Here we highlight that ET antagonizes BR response on the AOX capacity in papaya fruit ripening.

\section{BR content influences the AOX capacity in postharvest} papaya fruit: We provide the first evidence connecting $B R$ content and the maximum possible flux of electrons to AOX. In the present study, BR content was biochemically altered through the inhibition of BR biosynthesis (by Brz) or external supply of BR (by epiBR). As demonstrated, the stimulation of AOX pathway capacity by Brz was similar to that observed in fruit treated with epiBR. This suggests that the respective decrease or increase in BR content by Brz and epiBR could result in an intensified AOX capacity not related to BR content. Likewise, the maintenance of high capacity AOX pathway does not require high amounts of endogenous BRs.

Our data suggest that Brz suppresses epiBR-mediated induction of AOX activity in isolated mitochondria from fully ripened fruit. It is possible that the suppression of $\mathrm{BR}$ response by $\mathrm{Brz}$ reflect changes of $\mathrm{BR}$ content that would regulate the flux of mitochondrial electrons from reduced ubiquinone to the AOX pathway. For growth responses, the regulation of $\mathrm{BR}$ action by its own endogenous content through negative feedback was previously described (Tanaka et al. 2005).

BR biosynthesis inhibitors mimic the characteristics of tissues with BR deficiency (Asami et al. 2001). The marked effect of epiBR on fruit cotreated with $\mathrm{Brz}$ is probably due to a deficit of endogenous BRs. In BR-deficient mutants and BR inhibitortreated tissues, sensitivity to exogenously applied BR is increased in parallel with the upregulation of $\mathrm{BR}$ biosynthesis genes through negative feedback (Goda et al. 2002, Tanaka et al. 2005).

It is important to keep in mind that our measurements do not indicate the actual fluctuations of AOX capacity during ripening. It is important to emphasize that changes in respiration and ethylene emission are transient during papaya ripening (Bron and Jacomino 2006, Manenoi and Paull 2007). However, the increased ethylene emission in fully ripened papaya fruit was also found in previous results (e.g. Bron and Jacomino 2006), although our respiration values were relatively lower (Bron and Jacomino 2006). Our data also confirmed the fast ripening process in papaya fruit, even when ethylene emission was still relatively low. Some reports have shown that the softening of papaya can precede ethylene burst (Fabi et al. 2007, Bron and Jacomino 2006). Therefore, the question of whether these behaviors are specific to the ripening of papaya fruits or general characteristics of climacteric fruits is yet to be determined.

Interestingly, drastic differences in the AOX capacity between the two evaluated sampling times were not found. This could be because its actual activity was not evaluated. Although the fruits seemed to be in an advanced state of ripening (measured as loss of pulp firmness), the ethylene 
emission changed between both evaluations (Figure 1). Ethylene is considered as a key determinant of fruit ripening stage (Blankenship and Dole 2003, Fabi et al. 2010, Oliveira and Vitoria 2011). In addition, the whole fruit respiration induced by the treatment with Brz or epiBR alone in fully ripened fruit was simultaneous to higher AOX activity. However, the enhanced respiration and fruit softening that resulted from the combined application of Brz and epiBR were not correlated with enhanced AOX activity.

\section{BR effect on the capacity of AOX-dependent electron transport is antagonized by ethylene: Our evidence} also suggested that the effects of altered BR content are influenced by changes in ethylene response. The blockage of ethylene action seemed to directly or indirectly antagonize the effects of BR content on AOX capacity. The fact that the Brz or epiBR-decreased AOX capacity in fruit pre-incubated with 1-MCP was opposite to the increase detected in the absence of ethylene inhibitor supports this view. This opposite trend suggests that the increased AOX capacity by fluctuations in BR levels is downregulated by blocking ethylene action. Moreover, the treatment with epiBR enhanced AOX capacity. This BR in combination with Brz failed to increase AOX capacity in fruits cotreated with 1-MCP. This suggests that the BR-ET interaction may play a critical role in the regulation of AOX capacity.

It is well known that $1-\mathrm{MCP}$ antagonizes some ethylene responses in papaya fruit (Manenoi and Paull 2007, Fabi et al. 2007, Souza et al. 2009). A proper ethylene action probably

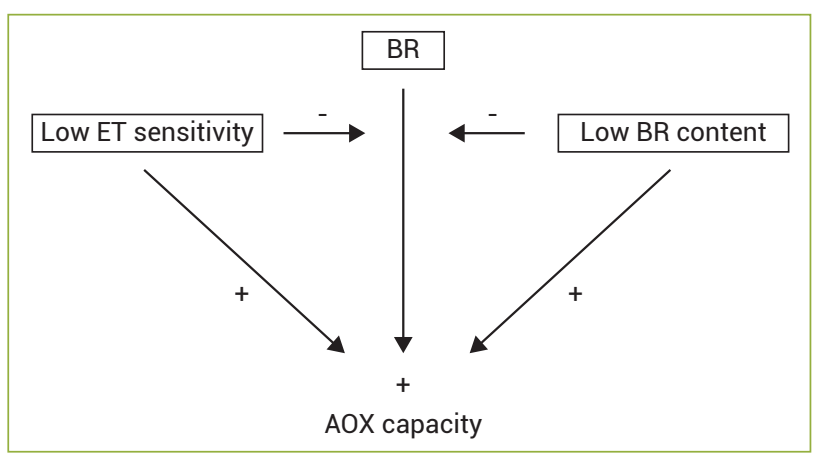

Figure 3. Hypothetical model of a possible interaction between $\mathrm{BR}$-ET effects on the mitochondrial electron transport related to the alternative oxidase (AOX) pathway during the ripening of postharvest papaya fruit. Applied BRs promote the AOX pathway. The effects of low ethylene (ET) sensitivity or low BR content could increase AOX capacity. However, the response of AOX capacity to external applied BR could be inhibited by the disruption of a proper BR/ET ratio. suppresses AOX capacity during the ripening of papaya fruit. In Arabidopsis plants, there are negative and positive interactions between BRs and ET (De Grauwe et al. 2005, Deslauriers and Larsen 2010). The opposite effects seen here indicate the possibility of a negative BR-ET interaction in papaya fruit ripening. Interestingly, Brz partially mimics the effect of 1-MCP on increasing AOX capacity. This suggests that the blockage of ethylene action and the reduction of BR content could have common effects. However, when combined, both chemicals inhibited the ability of epiBR to activate the AOX pathway capacity, suggesting that the BR/ET ratio is a critically defining BR action.

The high ethylene emission in the coapplication treatments suggests that Brz promoted the BR-mediated ethylene production, which in turn would suppress the BR effects on the AOX pathway. Some authors have reported increased ethylene production in fruit treated with BR (Vardhini and Rao 2002, Zaharah et al. 2011). Furthermore, applied BRs are able to accelerate fruit respiration (Zaharah et al. 2011). However, in fruit with BR synthesis decreased by Brz, respiration remained elevated. In agreement with our data, cucumber fruits were highly responsive to epiBR applications after the treatment with $4 \mu \mathrm{M}$ of a BR inhibitor ( $\mathrm{Fu}$ et al. 2008). Some previous reports indicated that endogenous $\mathrm{BR}$ content is low and may not be critical for fruit ripening (Zaharah et al. 2011, Symons et al. 2012). Our evidence suggests that endogenous BRs are not required to maintain fruit respiration.

Our data suggest that the interaction between BR and ET has effects on AOX pathway. Then, a hypothetical model of $\mathrm{BR} / \mathrm{ET}$ interaction is proposed in Figure 3. The exogenous application of BRs could promote the AOX pathway. The effects of lower ethylene (ET) sensitivity or BR content could increase AOX capacity. However, the enhanced AOX capacity in response to external applied BR is inhibited when the proper $\mathrm{BR} / \mathrm{ET}$ ratio is disrupted by these inhibitors. Generally, since it is well known that the shelf life of fruits is strongly related to respiratory activity, these results could have enormous practical relevance for the management of papaya fruit respiration by the combined modification of BR/ ET actions via specific chemicals.

\section{ACKNOWLEDGMENTS}

The authors are thankful to Caliman Agrícola S/A for the supply of fruit, FAPERJ, CNPq and CAPES for the financial support, and CAPES for the concession of fellowship grants. Thanks to CONICET (Argentine) for supporting Luis Miguel Mazorra and Carlos Guillermo Bartoli. 


\section{REFERENCES}

Almeida AM, Jarmuszkiewicz W, Khomsi H, Arruda P, Vercesi AE, Sluse FE (1999) Cyanide-resistant, ATP-synthesis-sustained, and uncoupling-protein-sustained respiration during postharvest ripening of tomato fruit. Plant Physiology 119:1323-1330.

Arteca RN, Arteca JM (2008) Effects of brassinosteroid, auxin, and cytokinin on ethylene production in Arabidopsis thaliana plants. Journal of Experimental Botany 59:3019-3026.

Asami T, Mizutani M, Fujioka S, Goda H, Min YK, Shimada Y, Nakano T, Takatsuto S, Matsuyama T, Nagata N, Sakata K, Yoshida S (2001) Selective interaction of triazole derivatives with DWF4, a cytochrome P450 monooxygenase of the brassinosteroid biosynthetic pathway, correlates with brassinosteroid deficiency in planta. Journal of Biological Chemistry 276:25687-25691.

Asami T, Nakano T, Nakashita H, Sekimata K, Shimada $\mathrm{Y}$, Yoshida $S$ (2003) The influence of chemical genetics on plant science: shedding light on functions and mechanism of action of brassinosteroids using biosynthesis inhibitors. Journal of Plant Growth Regulation 22:336-349.

Beavis AD, Vercesi AE (1992) Anion uniport in plant mitochondria is mediated by a $\mathrm{Mg}(2+)$-insensitive inner membrane anion channel. Journal of Biological Chemistry 267:3079-3087.

Blankenship SM, Dole JM (2003) 1-Methylcyclopropene: a review. Postharvest Biology and Technology 28:1-25.

Bradford MM (1976) A rapid and sensitive method for the quantitation of microgram quantities of protein utilizing the principle of protein-dye binding. Analytical Biochemistry 72:248-254.

Bron IU, Jacomino AP (2006) Ripening and quality of 'Golden' papaya fruit harvested at different maturity stages. Brazilian Journal of Plant Physiology 18:389-396.

Calegario FF, Cosso RG, Fagian MM, Almeida FV, Jardim WF, Jezek P, Arruda P, Vercesi AE (2003) Stimulation of potato tuber respiration by cold stress is associated with an increased capacity of both plant uncoupling mitochondrial protein (PUMP) and alternative oxidase. Journal of Bioenergetics and Biomembranes 35:21 1-220.

Carré JE, Affourtit C, Moore AL (2011) Interaction of purified alternative oxidase from thermogenic Arum maculatum with pyruvate. FEBS Letters 585:397-401.

Considine MJ, Daley DO, Whelan J (2001) The expression of alternative oxidase and uncoupling protein during fruit ripening in mango. Plant Physiology 126:1619-1629.

De Grauwe L, Vandenbussche F, Tietz O, Palme K, Van Der Straeten D (2005) Auxin, ethylene and brassinosteroids: tripartite control of growth in the Arabidopsis hypocotyl. Plant and Cell Physiology 46:827-836.

Deslauriers SD, Larsen PB (2010) FERONIA is a key modulator of brassinosteroid and ethylene responsiveness in Arabidopsis hypocotyls. Molecular Plant 3:626-640.

Duque P, Arrabaça JD (1999) Respiratory metabolism during cold storage of apple fruit. II. Alternative oxidase is induced at the climacteric. Physiologia Plantarum 107:24-31.
Fabi JP, Mendes LRBC, Lajolo FM, Nascimento JRO (2010) Transcript profiling of papaya fruit reveals differentially expressed genes associated with fruit ripening. Plant Science 179:225-233.

Fabi JP, Cordenunsi BR, de Mattos Barreto GP, Mercadante AZ, Lajolo FM, Oliveira do Nascimento JR (2007) Papaya fruit ripening: response to ethylene and 1-methylcyclopropene (1-MCP). Journal of Agricultural and Food Chemistry 55:6118-6123.

Fu FQ, Mao WH, Shi K, Zhou YH, Asami T, Yu JQ (2008) A role of brassinosteroids in early fruit development in cucumber. Journal of Experimental Botany 59:2299-2308.

Gendron JM, Haque A, Gendron N, Chang T, Asami T, Wang ZY (2008) Chemical genetic dissection of brassinosteroid-ethylene interaction. Molecular Plant 1:368-379.

Goda H, Shimada Y, Asami T, Fujioka S, Yoshida S (2002) Microarray analysis of brassinosteroid-regulated genes in Arabidopsis. Plant Physiology 130:1319-1334.

Jarmuszkiewicz W, Almeida AM, Vercesi AE, Sluse FE, SluseGoffart CM (2000) Proton re-uptake partitioning between uncoupling protein and ATP synthase during benzohydroxamic acid-resistant state 3 respiration in tomato fruit mitochondria. Journal of Biological Chemistry 275:13315-13320.

Lalel HJD, Singh Z, Tan SC (2003) Glycosidically-bound aroma volatile compounds in the skin and pulp of 'Kensington Pride' mango fruit at different stages of maturity. Postharvest Biology and Technology 29:205-218.

Manenoi A, Bayogan ERV, Thumdee S, Paull RE (2007) Utility of 1-methylcyclopropene as a papaya postharvest treatment. Postharvest Biology and Technology 44:55-62.

Manenoi A, Paull RE (2007) Papaya fruit softening, endoxylanase gene expression, protein and activity. Physiologia Plantarum 131:470-480.

Martins IS, Carnieri EGS, Vercesi AE (1993) Mechanisms of $\mathrm{Ca}^{2+}$ and anion transport across the inner membrane of plant mitochondria. Current Topics in Plant Physiology 1:211-217.

Moller IM, Bérczi A, van der Plas LHW, Lambers H (1988) Measurement of the activity and capacity of the alternative pathway in intact plant tissues: identification of problems and possible solutions. Physiologia Plantarum 72:642-649.

Oliveira JG, Vitoria AP (2011) Papaya: nutritional and pharmacological characterization, and quality loss due to physiological disorders. An overview. Food Research International 44:1306-1313.

Sekimata K, Kimura T, Kaneko I, Nakano T, Yoneyama K, Takeuchi Y, Yoshida S, Asami T (2001) A specific brassinosteroid biosynthesis inhibitor, Brz2001: evaluation of its effects on Arabidopsis, cress, tobacco, and rice. Planta 213:716-721.

Silva MG, Santos EO, Sthel MS, Cardoso SL, Cavalli A, Monteiro AR, Oliveira JG, Pereira MG, Vargas H (2003) Effect of heat treatment on ethylene and $\mathrm{CO} 2$ emissions rates during papaya (Carica papaya L.) fruit ripening. Review of Scientific Instruments 74:703-705. 
Souza MS, Azevedo IG, Corrêa SF, Silva MG, Pereira MG, Oliveira JG (2009) Responses of 1-MCP applications in 'Golden' papaya fruits on different maturation stages. Revista Brasileira de Fruticultura 31:693-700.

Symons GM, Chua YJ, Ross JJ, Quittenden LJ, Davies NW, Reid JB (2012) Hormonal changes during non-climacteric ripening in strawberry. Journal of Experimental Botany 63:4741-4750.

Tanaka K, Asami T, Yoshida S, Nakamura Y, Matsuo T, Okamoto $S$ (2005) Brassinosteroid homeostasis in Arabidopsis is ensured by feedback expressions of multiple genes involved in its metabolism. Plant Physiology 138:1117-1125.

Vanlerberghe GC (2013) Alternative oxidase: a mitochondrial respiratory pathway to maintain metabolic and signaling homeostasis during abiotic and biotic stress in plants. International Journal of Molecular Sciences 14:6805-6847.
Vardhini BV, Rao SS (2002) Acceleration of ripening of tomato pericarp discs by brassinosteroids. Phytochemistry 16:843-847.

Voesenek LA, Harren FJ, Bögemann GM, Blom CW, Reuss J (1990) Ethylene production and petiole growth in rumex plants induced by soil waterlogging: the application of a continuous flow system and a laser driven intracavity photoacoustic detection system. Plant Physiology 94:1071-1077.

Wills RBH, Widjanarko SB (1995) Changes in physiology, composition and sensory characteristics of Australian papaya during ripening. Australian Journal of Experimental Agriculture 35:1173-1176.

Zaharah SS, Singh Z, Symons GM, Reid JB (2012) Role of brassinosteroids, ethylene, abscisic acid, and indole-3-acetic acid in mango fruit ripening. Journal of Plant Growth Regulation 31:363-372.

\section{Supplementary Data}

Supplementary I: Skin color and pulp firmness in papaya fruit evaluated at $24 \mathrm{~h}$ and 5 days. Measurements were taken at three equidistant points around the equatorial zone of the fruit treated with $1 \mu \mathrm{M}$ 24-epibrassinolide (epiBR), or $10 \mu \mathrm{M} \mathrm{Brz2001}$ (Brz), or a combination of both compounds.

\begin{tabular}{lcccc} 
& \multicolumn{2}{c}{ Hue angle $\left({ }^{\circ} \mathrm{h}\right)$} & \multicolumn{2}{c}{ Pulp firmness (N) } \\
\cline { 2 - 5 } Treatments & $24 \mathrm{~h}$ after treatment & 5 days after treatment & $24 \mathrm{~h}$ after treatment & 5 days after treatment \\
Control & $105.6 \pm 3.8 \mathrm{a}^{*}$ & $82.5 \pm 3.2 \mathrm{a}$ & $28.0 \pm 6.0 \mathrm{a}$ & $0.84 \pm 0.4 \mathrm{a}$ \\
\hline epiBR & $106.3 \pm 2.3 \mathrm{a}$ & $80.5 \pm 1.5 \mathrm{a}$ & $24.0 \pm 3.0 \mathrm{a}$ & $0.70 \pm 0.2 \mathrm{a}$ \\
\hline Brz & $100.6 \pm 4.1 \mathrm{a}$ & $83.4 \pm 2.9 \mathrm{a}$ & $26.4 \pm 4.0 \mathrm{a}$ & $1.18 \pm 0.5 \mathrm{a}$ \\
\hline Brz+epiBR & $105.1 \pm 1.3 \mathrm{a}$ & $81.8 \pm 2.7 \mathrm{a}$ & $21.1 \pm 3.0 \mathrm{a}$ & $1.28 \pm 0.5 \mathrm{a}$
\end{tabular}

*Different letters indicate significant differences among treatments as compared to the respective control (Duncan's test, $p \leq 0.05)$.

Supplementary II: Skin color and pulp firmness in papaya fruit preincubated with 1-MCP and evaluated at $24 \mathrm{~h}$ and 5 days. Measurements were taken at three equidistant points around the equatorial zone of the fruit treated with $1 \mu \mathrm{M} 24$-epibrassinolide (epiBR), or $10 \mu \mathrm{M}$ Brz2001 (Brz), or a combination of both compounds.

\begin{tabular}{lcccc} 
& \multicolumn{2}{c}{ Hue angle $\left({ }^{\circ} \mathrm{h}\right)$} & \multicolumn{2}{c}{ Pulp firmness $(\mathrm{N})$} \\
\cline { 2 - 5 } Treatments & $\mathbf{2 4} \mathrm{h}$ after treatment & $\mathbf{5}$ days after treatment & $24 \mathrm{~h}$ after treatment & 5 days after treatment \\
$1-\mathrm{MCP}+$ Control & $113.7 \pm 0.7 \mathrm{a}^{*}$ & $80.4 \pm 7.6 \mathrm{a}$ & $84.7 \pm 5.6 \mathrm{a}$ & $1.3 \pm 0.6 \mathrm{a}$ \\
\hline $1-\mathrm{MCP}+\mathrm{epiBR}$ & $113.5 \pm 2.0 \mathrm{a}$ & $85.1 \pm 0.8 \mathrm{a}$ & $81.4 \pm 2.6 \mathrm{a}$ & $2.1 \pm 1.1 \mathrm{a}$ \\
$1-\mathrm{MCP}+\mathrm{Brz}$ & $112.8 \pm 1.0 \mathrm{a}$ & $84.6 \pm 1.2 \mathrm{a}$ & $73.7 \pm 5.7 \mathrm{a}$ & $3.7 \pm 2.1 \mathrm{a}$ \\
$1-\mathrm{MCP}+\mathrm{Brz}+$ epiBR & $111.1 \pm 0.8 \mathrm{a}$ & $87.5 \pm 1.1 \mathrm{a}$ & $71.3 \pm 10.2 \mathrm{a}$ & $3.1 \pm 0.9 \mathrm{a}$ \\
\hline
\end{tabular}

*Different letters indicate significant differences among treatments as compared to the respective control (Duncan's test, $p \leq 0.05)$. 